\title{
Validation of the Polish language version of the Patient Health Questionnaire-9 in a population of adults aged 35-64
}

\author{
Barbara Janina Ślusarska, ${ }^{1, A-D, F \oplus}$, Grzegorz Nowicki ${ }^{1, B-E}$, Honorata Piasecka ${ }^{1, B-E}$, Danuta Zarzycka ${ }^{2, C-F}$, \\ Anna Mazur ${ }^{3, C-F}$, Tomasz Saran, ${ }^{3, C-F}$, Anna Bednarek ${ }^{2, C-E}$ \\ 1 Department of Family Medicine and Community Nursing, Faculty of Health Sciences, Medical University, Lublin, Poland \\ ${ }^{2}$ Chair and Department of Paediatric Nursing, Faculty of Health Sciences, Medical University, Lublin, Poland \\ ${ }^{3}$ Department of General and Neuro Rehabilitation, Witold Chodźko Institute of Rural Health, Lublin, Poland \\ A - Research concept and design, B - Collection and/or assembly of data, C - Data analysis and interpretation, \\ $D$ - Writing the article, $E$ - Critical revision of the article, $F$ - Final approval of article
}

Ślusarska BJ, Nowicki G, Piasecka H, Zarzycka D, Mazur A, Saran T, Bednarek A. Validation of the Polish language version of the Patient Health Questionnaire-9 in a population of adults aged 35-64. Ann Agric Environ Med. 2019; 26(3): 420-424. doi: 10.26444/aaem/99246

\section{Abstract}

Introduction. Depressive disorders are one of the most common psychiatric disorders. Recognition of signs of mental health disorders is not always easy, hence the availability of simple and accurate tools for assessing them is very important in the practice of primary care.

Objective. The aim of the study is to assess the theoretical accuracy and reliability of the Patient Health Questionnaire-9 (PHQ-9) in Polish conditions, when applied to general population studies for adults aged between 35-64.

Materials and method. The study comprised a population of 4,040 people. Women constituted $59 \%$ of the research population and people living in the countryside $65 \%$. The average age of participants was $53.45 \pm 7.05$ years. According to PHQ-9, 727 people (18.0\%) had moderate, moderate to severe or severe depression. PHQ-9 showed a significant positive internal cohesion (Cronbach's alpha $=0.77$ ), and factor charges oscillated between $0.43-0.63$, and the $\mathrm{R}^{2}$ coefficients of determination were in the range of $0.21-0.40$.

Conclusions. The Polish version of PHQ-9 is a valid tool for diagnosing depression in the general population aged 35-64. Good psychometric properties and compactness make the PHQ-9 a useful clinical and research tool.

\section{Key words}

PHQ-9, depression severity, general population, psychometric assessment

\section{INTRODUCTION}

Mental health disorders are a significant epidemiological and social issue. Depressive disorders are one of the most common mental disorders. Depression is a particular type of mood, emotion and activity disorder including lowered mood, psychomotor activity, disorders of daily routine, somatic symptoms, thinking disorders and complex activity disorders [1]. According to the criteria of the World Health Organization (ICD-10), an episode of depression is characterized by the presence of specific symptoms persisting for at least two weeks [2].

Depression has an indisputable, negative impact on all spheres of human life - from the emotional sphere, through physical efficiency, cognitive functions, and ending with social relations. It also constitutes an important risk factor for other diseases [3].

In Poland, the first broad epidemiological study of psychiatric disorders, called EZOP according to the WHO methodology, was conducted in 2010-2011 on a representative group of adults $(n=10,081)$ aged $18-64$. The research results indicate that mood disorder rate in the respondents was $3.5 \%$ in total, including an up to $3 \%$ depression rate [4]. According

Address for correspondence: Barbara Janina Ślusarska, Department of Family Medicine and Community Nursing, Faculty of Health Sciences, Medical University of Lublin, Staszica 6/10, 20-081 Lublin, Poland

e-mail: basiaslusarska@gmail.com

Received: 19.07.2018; accepted: 27.10.2018; first published: 28.11.2018 to the cited study, 766 thousand people have experienced a depressive episode in their lifetime.

The study of the prevalence of depressive disorders according to ICD-10 criteria among Primary Healthcare Units (pol. "POZ") patients in Poland, carried out in 2007, demonstrated that the criterion of depression was met by $23 \%$ of those examined [5].

Multifactorial etiology of depression and the "masked" nature of symptoms in the clinical picture generate diagnostic problems, hindering early diagnosis and the introduction of appropriate treatment. In the national system of primary healthcare there is a lack of screening tests for the general population which would give the opportunity for a quick and early assessment of these disorders. Due to untreated depression the risk of suicides and deaths increases. Furthermore, untreated depression results in the development of somatic diseases, on the other hand somatic diseases contribute to the development of depression [6].

In an initial diagnosis among the general population, diagnostic depression screening tools become desired. Nationally and worldwide, the most commonly implemented tools include: the Beck Depression Inventory (BDI) [7], the Patient Health Questionnaire - 9 (PHQ-9) [8], the Hospital Anxiety and Depression Scale (HADS) [9], and the Geriatric Depression Scale Short Form (GDS-SF) [10]. The aforementioned diagnostic tools were developed in English and then translated into other languages. However, their translations are often implemented without validation [11]. 
The diagnosis of mental health disorders is arduous. The Patient Health Questionnaire-9 (PHQ-9) is a concise diagnostic instrument for screening, diagnosing depression used by healthcare professionals. The Patient Health Questionnaire-9 (PHQ-9) is a part of a larger tool kit: the Patient Health Questionnaire [8]. The questionnaire was developed based on the depression diagnostic criteria taken from the Diagnostic and Statistical Manual of Mental Disorders (DSM-IV). To date, these criteria have not undergone any significant changes in the DSM-V [12]. The 9-question depression scale items correspond to the particular symptoms of depression included in the DSM-IV and DSM-V diagnostic criteria.

In the Polish language version, the PHQ-9 instrument was made available by Pfizer Inc. at the internet address http:// www.phqscreeners.com. Easy access to the Polish version of the tool may have resulted in its application in empirical practice without checking its psychometric properties.

Currently, available Polish research by Tomaszewski, Zarychta, Bieńkowska et al. [13] has confirmed the suitable psychometric properties of the PHQ-9 instrument in the Polish language version, and recommend the questionnaire as a useful depression screening instrument among hospitalized elderly people $(n=105$; mean age $=73.4$; $\mathrm{SD}=7.9$ years). In 2016, the results of psychometric evaluation of the Polish version of the PHQ-9 scale were published for the group of people aged $18-60(n=99$; mean age $=41 ; \mathrm{SD}=12.5)$ hospitalized in the Department of Internal Diseases, Nephrology and Transplantology of the Central Clinical Hospital of the Ministry of Interior and Administration, and in the Daytime Psychiatric Ward of the Bródno Hospital (Brodnowski County Hospital), both in Warsaw, and among random people who consented to participate. Reliability analysis assessed by the Cronbach's alpha indicatorfor PHQ9 was 0.88 , demonstrated a very good internal coherence. The assessment of convergent accuracy for results of PHQ-9 demonstrated a strong correlation with the assessment of the state of depression according to Beck Depression Inventory - BDI (rho $=0.92, \mathrm{p}<0.001$ ) and depression rating by the Hamilton Depression Scale - HDRS (rho $=0.87, \mathrm{p}<0.001$ ) [14].

In Polish literature, however, the psychometric evaluation of the PHQ-9 tool is still missing in relation to the general population of adults in order to check its theoretical accuracy, reliability and sensitivity to recognize the signs of depressive disorders without specific features that increase the risk of depression, e.g. geriatric age or burden associated with hospitalization due to illness.

\section{OBJECTIVE}

The purpose of the research is to assess the validity and the reliability of the PHQ-9 scale in Polish conditions in general population studies in relation to adults aged 35-64.

\section{MATERIALS AND METHOD}

The assessment of the accuracy and reliability of the PHQ9 scale was carried out based on a cross-sectional study in 2015-2016 among 4,040 residents of Janów District (pol. "Powiat") aged 35-64. The tests were carried out as part of the project entitled "Weź sobie zdrowie do serca - program profilaktyki i promocji zdrowia $w$ zakresie chorób układu krążenia w powiecie janowskim" ("Follow Your Heart" programme concerning the awareness of cardiovascular diseases in the Janów District") financed by the Norwegian Financial Mechanism 2009-2014 under the PL Program 13 "Limiting social inequities in health" and the State budget. 47,500 people lived in the Janów District in the period subjected to analysis. There were 18,827 residents in the group aged between 35-64 years (data provided by the Central Statistical Office (GUS), BDL for 2014). There were 4,040 people from the selected age group included in the study, which accounted for $21.45 \%$ of this part of the population.

Patient Health Questionnaire - PHQ-9. The Polish version of PHQ-9, made available by Pfizer Inc. at the internet address http://www.phqscreeners.com was utilized for the study.

PHQ-9 is a questionnaire consisting of 9 basic questions and one additional question. The answer to each question is scored on a scale from $0-3$, depending on the frequency of a given symptom in the last 2 weeks ( 3 points indicate the most frequent occurrence of the symptom). The diagnosis includes following severity stages: 0-4 none, 5-9 mild depression, 1014 moderate depression, 15-19 moderately severe depression, 20-27 severe depression [15].

Statistical analysis. Data was expressed as mean and standard deviation (SD). The Shapiro Wilk test was used to assess conformity with a normal distribution. The relationship between the examined variables was determined using a non-parametric chi-square test.

To confirm the 1-factor structure of the PHQ-9 tool, a confirmatory factor analysis (CFA)was performed with use of the AMOS 20.0 software suite. The Cronbach's alpha internal reliability estimate was used to assess the reliability of the scale.

Ethical requirements. The research was voluntary and anonymous. Respondents consciously gave consent to participate in the research and provided their written consent. The research received approval from the Bioethical Commission of the Medical University in Lublin (No. KE0254/112/2014), and was conducted in accordance with the Helsinki Declaration.

\section{RESULTS}

Characteristics of the examined group. The examined group $(\mathrm{n}=4,040)$ consisted mainly of women $(59 \%)$ and people living in rural areas (65\%). The average age of respondents was $53.45 \pm 7.05$ years. The respondents most often had vocational (38\%) and secondary (32\%) education. Over $86.7 \%$ of respondents were married (Tab. 1).

Results of depressive disorders by PHQ-9 in the study group. It was observed that in the study group, according to the PHQ-9 test, $18.0 \%$ of the respondents had moderate, moderate-to-severe or severe depression. Men (33.8\%) were more likely to have a test in the limits of the normal value than women (27.7\%). Among women, there was a significantly higher, statistically significant percentage of participants with moderate depression ( $\mathrm{p}<0.001)$ (Tab. 2). 
Table 1. Socio-demographic and medical characteristics of the respondents

\begin{tabular}{|c|c|}
\hline Variable & $\mathrm{N}=4040(\%)$ \\
\hline \multicolumn{2}{|l|}{ Gender } \\
\hline Females & 2367 (59.0\%) \\
\hline Males & $1673(41.0 \%)$ \\
\hline \multicolumn{2}{|c|}{ Age [years]: average ( \pm SD) $53.45 \pm 7.05$} \\
\hline 44 and less & $582(14.4 \%)$ \\
\hline $45-54$ & $1454(36.0 \%)$ \\
\hline $55-64$ & $2004(49.6 \%)$ \\
\hline \multicolumn{2}{|l|}{ Place of residence } \\
\hline Rural & $2652(65.0 \%)$ \\
\hline Urban & $1388(35.0 \%)$ \\
\hline \multicolumn{2}{|l|}{ Education } \\
\hline Primary & $461(11.0 \%)$ \\
\hline Vocational & $1510(38.0 \%)$ \\
\hline Secondary & $1280(32.0 \%)$ \\
\hline Higher & 775 (19.0\%) \\
\hline \multicolumn{2}{|l|}{ Marital status } \\
\hline Married & $3544(87.7 \%)$ \\
\hline Single (spinster/bachelor) & $247(6.1 \%)$ \\
\hline Widow/Widower & 249 (6.2\%) \\
\hline \multicolumn{2}{|l|}{ Medical history } \\
\hline Previous heart attack & $97(2.4 \%)$ \\
\hline Previous stroke & $77(1.9 \%)$ \\
\hline Ischaemic heart disease & $226(5.6 \%)$ \\
\hline Arterial hypertension & 1337 (33.1\%) \\
\hline Hyperlipidaemia & $513(12.7 \%)$ \\
\hline Diabetes & $218(5.4 \%)$ \\
\hline
\end{tabular}

Table 2. Results of the PHQ-9 test in the study group

\begin{tabular}{lcccccc}
\hline \multirow{2}{*}{ PHQ-9 TEST } & \multicolumn{2}{c}{ In total } & \multicolumn{2}{c}{ Women } & \multicolumn{2}{c}{ Men } \\
\cline { 2 - 8 } & $n$ & $\%$ & $n$ & $\%$ & $n$ & $\%$ \\
\hline Normal (<5pts) & 1,119 & 27.7 & 549 & 23.2 & 565 & 33.8 \\
\hline Mild depression (5-9 points) & 2194 & 54.3 & 1291 & 54.5 & 903 & 54.0 \\
\hline Moderate severity (10-14 points) & 610 & 15.1 & 436 & 18.4 & 178 & 10.6 \\
\hline Moderate to severe (15-19pts) & 89 & 2.2 & 69 & 2.9 & 22 & 1.3 \\
\hline Severe depression (20-27 points) & 28 & 0.7 & 22 & 0.9 & 5 & 0.3 \\
\hline Total & $\mathbf{4 0 4 0}$ & $\mathbf{1 0 0 . 0}$ & $\mathbf{2 3 6 7}$ & $\mathbf{1 0 0 . 0}$ & $\mathbf{1 6 7 3}$ & $\mathbf{1 0 0 . 0}$ \\
\hline Chi-square $=67.045 ; \mathrm{df}=4 ; \mathrm{p}<0.001$ & & & & &
\end{tabular}

Psychometric properties of the PHQ-9 scale. In the analysis, a univariate structure was distinguished. In the initial solution (Model 1), the strength of the construct's influence on the intensity of observational variables oscillated within $(\lambda-G r$. lambda) between $0.44-0.62$ (factor load). Values of determination coefficients (correlation factor $-\mathrm{R}^{2}$ ) fluctuated between $0.18-0.46$. This model was characterized by an incompletely satisfying adjustment to the data. During the analysis, it turned out that there is a pair of positions ( 1 and 2) with correlated error variances (Model 2). In Model 2, the values of $\lambda$ oscillated between $0.43-0.63$ and the coefficients of determination $\mathrm{R}^{2}$ were in the range of $0.21-0.40$. Positive and high track loads are a condition for the occurrence of internal homogeneity of the scale. Model 2 proved to be better suited to the data than Model 1 (Tab. 3). Estimates were obtained by the Restricted Maximum Likelihood, RML method.

Table. 3. Matching properties of both analyzed models ${ }^{1}$

\begin{tabular}{lccccccc}
\hline & Chi $^{2}$ & df & $p$ & CFI & AGFI & RMSEA & Cl90 \\
\hline Model 1 & 428.133 & 27 & $<0.001$ & 0.940 & 0.960 & 0.061 & $0.056 ; 0.066$ \\
\hline Model 2 (RML) & 237.649 & 26 & $<0.001$ & 0.968 & 0.977 & 0.045 & $0.040 ; 0.050$
\end{tabular}

1 RMSEA (Root mean square error of approximation) - Steiger Lind test, which is a measure of how badly the model is adjusted, including its parameters that require estimation; the closer its result is to 0 , the better the matching of the theoretical model to the result matrix; an index not exceeding 0.05 means a good fit, a result below 0.08 is considered acceptable; AGFI>0.8 adjusted goodness of fit index, a measure analogous to the corrected coefficient of determination in regression models, in which the number of degrees of freedom regarding the number of variables is taken into account; CFI>0.9 (Confirmatory Fit Index) - this index takes values from 0 to 1 , where 1 means a perfectly fitted model.

${ }^{2}$ When the data is continuous and the distribution is not multidimensional normal, the restricted maximum likelihood method (RML) or the ADF (asymptotically distribution free) method, which is insensitive to distribution (RML) ar he ADF (asy mich is insensitive to distribution or, according to the translation proposed by A. Sagan - nonparametric, independent of distribution. However, the ADF requires a sample of over 5,000
observations

The chi-square test results were statistically significant; nonetheless, the test result was strongly dependent on the sample size, number of variables, number of free parameters, or deviations from the normality of the distribution. Other adjustment measures were referenced, and their values were acceptable, indicating appropriateness of the empirical data to the model.

The matching indicators demonstrate that the model fits well with the data, which denotes the factor relevance of the construct (the construct is one-dimensional).

The internal compatibility of the 9-point scale is $\alpha=0.77$ and is satisfactory from the point of view of empirical research (Cronbach's alpha). The removal of any item does not improve the overall compatibility of the internal scale. The skewness and kurtosis of item 9 proved to be the sole issue.

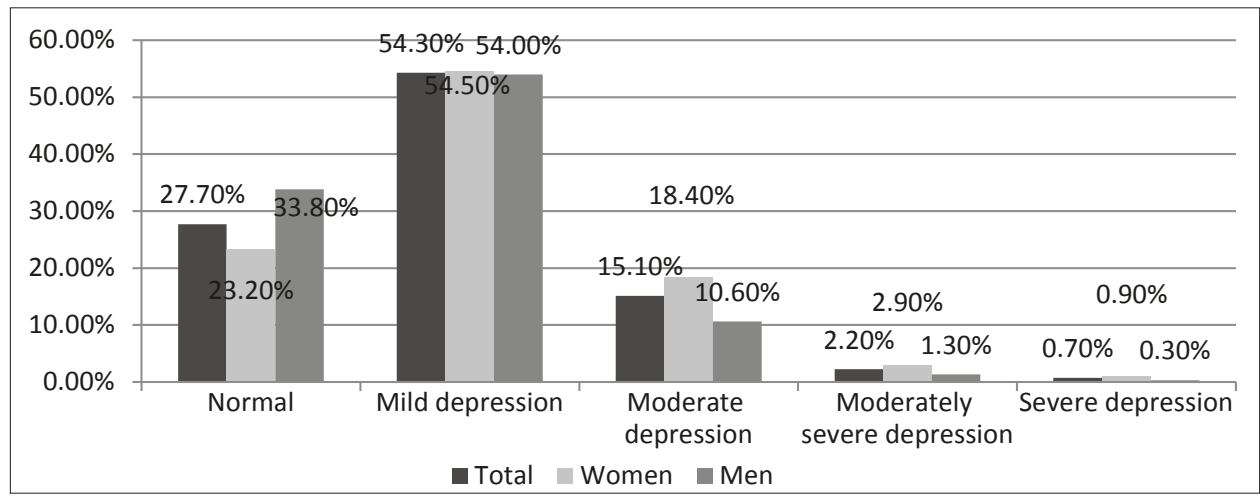

Figure 1. Graphical distribution of PHQ-9 test results in the study group $(n=4,040)$ 
Table 4. Properties of individual PHQ-9 items

\begin{tabular}{|c|c|c|c|c|c|c|c|c|c|}
\hline PHQ-9 & $\mathrm{N}$ & Min & Max & M & SD & As & $\mathrm{K}$ & ri-wo & alfai-1 \\
\hline I have little interest or pleasure in doing things & 4040 & 1 & 4 & 1.82 & 0.65 & 0.59 & 0.94 & 0.45 & 0.75 \\
\hline I feel down, depressed and hopeless & 4040 & 1 & 4 & 1.67 & 0.62 & 0.76 & 1.61 & 0.57 & 0.73 \\
\hline I have trouble falling asleep or sleeping, or sleep too much & 4040 & 1 & 4 & 1.84 & 0.79 & 1.03 & 1.09 & 0.38 & 0.76 \\
\hline I feel tired, I have little energy & 4040 & 1 & 4 & 2.18 & 0.68 & 1.30 & 2.01 & 0.48 & 0.74 \\
\hline I am overeating or have poor appetite & 4040 & 1 & 4 & 1.93 & 0.72 & 0.93 & 1.53 & 0.40 & 0.76 \\
\hline I have trouble concentrating when reading a newspaper or watching television & 4040 & 1 & 4 & 1.60 & 0.67 & 1.11 & 1.68 & 0.47 & 0.75 \\
\hline I speak and/or move too slowly or too fast & 4040 & 1 & 4 & 1.79 & 0.76 & 1.02 & 1.21 & 0.46 & 0.75 \\
\hline I think I would be better off dead & 4040 & 1 & 4 & 1.13 & 0.40 & 3.62 & 16.42 & 0.40 & 0.76 \\
\hline
\end{tabular}

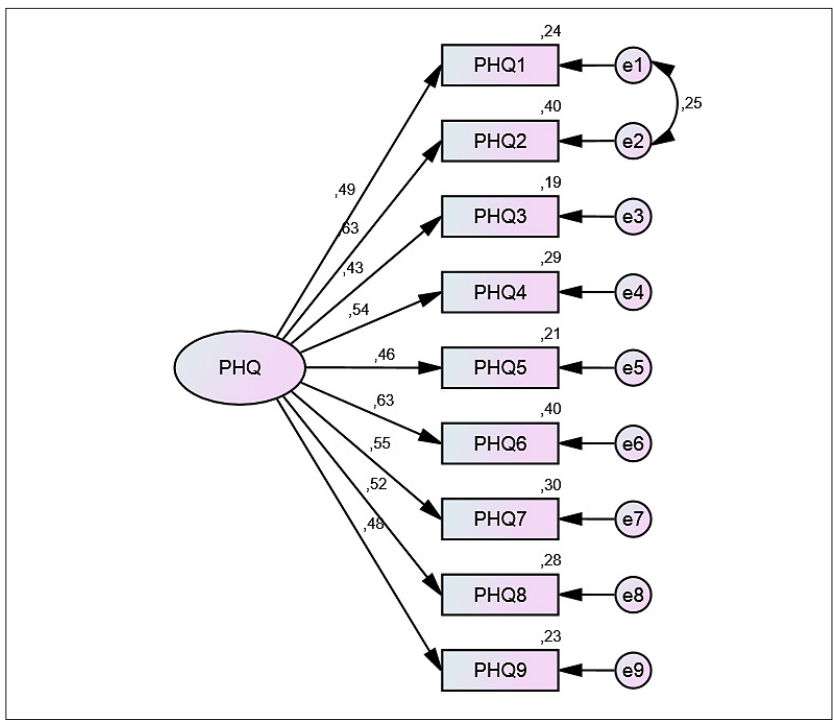

Figure 2. Confirmation analysis model for the PHQ-9 questionnaire

Most probably, this resulted from a very extreme formulation of the theorem (Fig. 2; Tab. 4).

\section{DISCUSSION}

The results obtained in the study confirm that the Polish version of PHQ-9 is a tool with satisfactory psychometric properties (Cronbach's alpha $=0.77$ ) for the group of adults aged $35-64$, which may be applicable to screening for depression in the general population of adult Poles. The Cronbach alpha value is lower than in the original study by Kroenke, Spitzer and Williams [15], conducted in a group of 3,000 primary care patients and 3,000 people in maternity and gynecological clinics. The internal reliability of PHQ-9 was excellent, with Cronbach's alpha $\alpha=0.89$ in the PHQ Primary Care Study and $\alpha=0.86$ in the PHQ Ob-Gyn study [15]. The obtained results are slightly lower in this respect, also in comparison with the results of the Polish study in the group of hospitalized persons $(n=99)$ where the Cronbach's alpha for PHQ-9 was 0.88 [14]. The obtained reliability of the PHQ-9 test proved to be slightly higher than for the group of Polish seniors $(\mathrm{n}=105)$, where the PHQ-9 demonstrated only good internal consistency (Cronbach's alpha coefficient $=0.7$ ) [13].

Differences in the results of PHQ-9 reliability in various studies may stem from a greater variation in the participants in the discussed studies due to the structure of gender, age or medical conditions. This can also be observed in numerous groups and populations whose validation results are described in English literature. Research conducted in primary care in Scotland $(n=1,063)$ concerning the PHQ-9 instrument showed high internal consistency (Cronbach's alpha $=0.83)[16]$.

In research by Wang, Bian, Zhao et al.[17], the reliability of the Chinese version of PHQ-9 in detecting depression among the residents of that community $(n=1,045)$ resulted in Cronbach's alpha $=0.86$. In the study of the reliability of the Arabic version of PHQ-9 in a group of students of the King Saud University in Riyadh ( $\mathrm{n}=731$ ), the obtained Cronbach's alpha coefficient was $=0.85$ [18].

Undoubtedly, it is crucial to provide effective screening methods for population depression that are directly related to primary care systems in order that patients with depressive disorder are adequately treated. This is especially important as an effective treatment of depression, not only to reduce symptoms associated with the disease and to decrease the risk of suicide, but also to improve the functioning and offset the negative effects that depressive symptoms can have on the physical well-being of adults.

The US Preventive Services Task Force Report (USPSTF) from 2002 enumerates crucial recommendations for such a tool kit, i.e. sufficiently reliable assessment scales reported by patients with depression are readily available and useful in primary care, and such screening tests that can lead to a thorough diagnosis and treatment of depression symptoms in primary care. When considering screening tools, the Patient Health Questionnaire (PHQ-9) appeared as the first choice for the majority of primary care facilities and adult populations. This instrument can accurately identify about $80 \%$ of "actual" cases, with a positive predictive value of around 50\% [19]. Physicians should be aware that such sensitivity, although acceptable for screening, does not mean that a lower result excludes the diagnosis of depression (about 1 in 5 real cases, score below the threshold), and that in the second half the "positive" result will be related to symptoms that can be attributed to other disorders [20].

In Polish studies carried out by Kokoszka et al. [14] in a group of 99 people, the best combination of sensitivity and specificity for the PFQ-9 scale, $82 \%$ and $89 \%$ respectively, was achieved at the cut-off point of 12 , which means that the mentioned sensitivity and specificity in the diagnosis of the depressive episode, the results are $>12$ points on the scale.

Nevertheless, the implemented validation studies have some limitations. The limitation of this study is the lack of 
assessment of relevance to other tools used to assess depression in the general population, e.g. the Beck Depression Inventory (BDI). Additionally, the study did not include assessment of the sensitivity and specificity of the scale to determine the cut-off threshold guaranteeing the greatest sensitivity and specificity for the diagnosis of depression in the general population. However, care has been taken to ensure that the study covers a large and diversified group of people, including those who are completely healthy, people with risk factors and respondents diagnosed with chronic diseases, among whom the occurrence of depressive symptoms is higher than in the general population. It is undoubtedly a larger group $(n=4,040)$ and differs from the respondents in validation studies of the Polish language version of PHQ-9 for older people, which included 105 people hospitalized in the Department of Internal Medicine and Geriatrics [12] and for those aged 18-60 $(n=99)$ hospitalized in the Department of Internal Diseases, Nephrology and Transplantology of the Central Clinical Hospital of the Ministry of Interior and Administration in Warsaw, in the Daytime Psychiatric Ward of the Bródno Hospital (Brodnowski County Hospital, also in Warsaw, and among people who expressed their consent to participate [14].

\section{CONCLUSIONS}

The Polish version of PHQ-9 is a good tool for diagnosing depressive disorders in a specific general population aged 3564 , based on the diagnostic criteria of depression contained in the Diagnostic and Statistical Manual of Mental Disorders. The adjustment indicators show that the model fits well with the data, which confirms the accuracy of the tool and indicates that it is consistent with the assumed theoretical construct. The acceptable (Cronbach's alpha of 0.77) internal consistency and conciseness make the PHQ-9 a useful clinical and research tool.

\section{REFERENCES}

1. Rybakowski J, Pużyński S, Wciórka J. (eds). Psychiatria. T. 2. Wrocław: Elsevier Urban \& Partner, 2010, pp. 305-375.

2. Pużyński S, Wciórka J. Klasyfikacja zaburzeń psychicznych i zaburzeń zachowania w ICD-10. Opisy kliniczne i wskazówki diagnostyczne. Kraków: UWM Vesalius, 2007, pp. 107-116.

3. Kessler RC, Bromet EJ. The epidemiology of depression across cultures. Annu Rev Public Health 2013; 34(1): 119-138.
4. Kiejna A, Piotrowski P, Adamowski T, et al. Rozpowszechnienie wybranych zaburzeń psychicznych w populacji dorosłych Polaków z odniesieniem do płci i struktury wieku - badanie EZOP Polska. Psychiatr Pol. 2015; 49: 15-27.

5. Drożdż W, Wojnar M, Araszkiewicz A, et al. The study of the prevalence of depressive disorders in primary care patients in Poland. Wiad Lek. 2007; 60: 109-113.

6. Osińska M, Kazberuk A, Celińska-Janowicz K, Zadykowicz R, Rysiak E. Depression - civilization disease of the 21st century. Geriatria 2017; 11: 123-129.

7. Beck AT, Ward CH, Mendelson M, Mock J, Erbaugh J. An inventory for measuring depression. Arch Gen Psychiatry. 1961; 4: 561-571.

8. Spitzer RL, Kroenke K, Williams JB. Validation and utility of a selfreport version of PRIME-MD: The PHQ Primary Care Study. JAMA 1999; 282: 1737-1744.

9. Zigmond AS, Snaith RP. The Hospital Anxiety and Depression Scale. Acta Psychiatr Scand. 1983; 67: 361-370.

10. Yesavage JA, Brink TL, Rose TL, Lum O, Huang V, Adey M, Leirer VO. Development and validation of a geriatric depression screening scale: A preliminary report. J Psychiatr Res. 1983; 17: 37-49.

11. Jasik K, Jaślikowska U, Zbrojkiewicz M, Ślusarska B, Jasińska M, Grzegorczyk M, Nowicki G. Factors related to occurrence of depressive disorders in adults. A systematic review of Polish literature in years 2009-2014. J Educ Health Sport. 2016; 6(4): 297-318. doi: http://dx.doi. org/10.5281/zenodo.50206

12. American Psychiatric Association: Diagnostic and Statistical Manual of Mental Disorders, Fifth Edition (DSM-5). American Psychiatric Association, Washington DC 2013.

13. Tomaszewski K, Zarychta M, Bieńkowska A, Chmurowicz E, Nowak W, Skalska A. Validation of the Patient Health Questionnaire-9 Polish version in the hospitalized elderly population. Psychiatr Pol. 2011; $\mathrm{XLV}(2): 223-233$.

14. Kokoszka A, Jastrzębski A, Obrębski M. Psychometric properties of the polish version of Patient Health Questionnaire-9. Psychiatry 2016; 13, 4: 187-193.

15. Kroenke K, Spitzer RL, Williams JBW, The PHQ-9 Validity of a Brief Depression Severity Measure. J Gen Intern Med. 2001 16(9): 606-613. doi: 10.1046/j.1525-1497.2001.016009606.x

16. Cameron IM, Crawford JR, Lawton K, Reid IC. Psychometric comparison of PHQ-9 and HADS for measuring depression severity in primary care. British J General Practice 2008; 58: 32-36. DOI: 10.3399/bjgp08X263794

17. Wang W, Bian Q, Zhao Y, Li X, Wang W, Du J, Zhang G, Zhou Q, Zhao M. Reliability and validity of the Chinese version of the Patient Health Questionnaire (PHQ-9) in the general population. Gen Hosp Psychiatry. 2014; 36(5): 539-44. doi: 10.1016/j.genhosppsych.2014.05.021.

18. AlHadi AN, AlAteeq DA, Al-Sharif E, Hamdah M, Bawazeer HM, Alanazi H, AlShomrani AT, Shuqdar RM, AlOwaybil R. An arabic translation, reliability, and validation of Patient Health Questionnaire in a Saudi sample. Ann Gen Psychiatry 2017; 16: 32. https://doi. org/10.1186/s12991-017-0155-1

19. Siu AL, US Preventive Services Task Force. Screening for depression in adults: US Preventive Services Task Force Recommendation Statement. JAMA. 2016; 315(4): 380-387. doi:10.1001/jama.2015.18392

20. Thase TE. Recommendations for Screening for Depression in Adults. JAMA. 2016; 315(4): 349-350. doi:10.1001/jama.2015.18406 